\title{
Effectiveness of a School-Based Indicated Early Intervention Program for Māori and Pacific Adolescents
}

\author{
Barbara Woods ${ }^{1}$ and Paul E. Jose ${ }^{2}$ \\ 'St Mary's College, Wellington, New Zealand \\ 2 Victoria University of Wellington, New Zealand
}

\begin{abstract}
This study set out to determine the efficacy of a school-based early intervention program (the Kiwi ACE program) with Māori and Pacific adolescents experiencing depressive symptoms. A large group $(N=419)$ of Māori and Pacific students (average age 14 years) was screened for depressive symptoms and, from a pool of students scoring greater than 63 on the Children's Depression Inventory (CDI), 56 students were randomly assigned to either an intervention or control group. After attrition, the final sample constituted 24 young people after one year. The intervention comprised eight 90minute sessions conducted in school time. Students were taught to more fully understand the relationships between thinking, feeling and behaviour, to challenge beliefs and to solve interpersonal problems. At immediate posttest $(p=.045)$ and at one-year follow-up $(p<.001)$ a significant effect for condition was obtained: the intervention group reported lower depressive symptoms. Efficacy of the intervention was supported by qualitative data obtained from focus groups. Further controlled trials on a larger scale are recommended to establish the durability and generalisability of the effects of program participation.
\end{abstract}

Keywords: Māori, Pacific, adolescent, depression, prevention

Depression is the leading cause of disability worldwide and is acknowledged internationally as a problem of increasing concern (World Health Organization, 2005). Depressive episodes are occurring at an earlier age than previously (Joyce, Oakley-Browne, Wells, Bushnell, \& Hornblow, 1990; Parker \& Roy, 2001), with particularly early episodes being predictive of later adult depression. Multiple risks have been noted to be associated with depression in adolescence, including poorer social and academic functioning (Harrington, 2001), poorer mental health and life course outcomes in early adulthood (Fergusson, Boden, \& Horwood, 2007; Berndt et al., 2000), increased risk of suicidal behaviour (National Institute of Mental Health, 2000), multiple sexual partners, increased risk for pregnancy (DiClemente, 2001), progression to problematic drug use (Hauenstein, 2003) and serious mental health difficulties (Rao, 2001).
International figures for adolescent depression show that rates are increasing (Costello et al., 2002) and that young men's rates are of especial concern (World Health Organization, 2005). New Zealand statistics for adolescent depression in 2001 report that $26.5 \%$ of females and $9.7 \%$ of males experience a major depressive episode by the age of 18 years (Fergusson \& Horwood, 2001). Studies published subsequently show some improvement at $15 \%$ of females and $7 \%$ of males (Adolescent Health Research Group, 2008). First onset is commonly reported as being between 15 and 19 years of age, and a typical depressive episode lasts on average between seven to nine months.

National data for Māori adolescents in New Zealand (Adolescent Health Research Group, 2001) indicate that $22.7 \%$ of Māori females and $9.9 \%$ of Māori males reported significant depressive symptoms on the Reynolds Adolescent Depression scale. Figures are not 
yet available nationally for Pacific students, but the first author's earlier study (Woods, 2001) revealed that $18.7 \%$ of Māori and Pacific students screened for depressive symptoms in the Wellington area in 2001 scored over 63 on the Children's Depression Inventory (CDI) (compared with $10.8 \%$ of students for the whole sample). The current study found $19.8 \%$ of Māori and Pacific students scoring over 63 on the CDI compared with $12.3 \%$ for the whole sample. Thus, research evidence seems to suggest that Mãori and Pacific young people report higher levels of depressive symptoms than the overall sample in New Zealand. However, since these measures have not been normed on Māori and Pacific youth, caution should be exercised in concluding that identical scores indicate identical levels of symptoms across groups.

In other domains Māori and Pacific young people are also overrepresented in the problematic range. Educational outcomes for Māori and Pacific students are showing improvement but disparities remain when compared with New Zealand students at large (Horomia, 2007). Māori and Pacific young people are much more likely to leave school with no or few qualifications, and higher rates of unemployment are experienced in the years after leaving secondary school (Jacobsen et al., 2002). Data for hospitalisation for self-inflicted injury for young people aged 15-19 years in New Zealand in 2005 $(15.3 \%)$ show that the risk for Māori is $1 \frac{1 / 2}{2}$ times that for non-Māori (Ministry of Health, 2006). On the other hand, the risk for Pacific adolescents is half that of Māori (Beautrais, 2001). Similar but not identical rates were obtained by the Youth2000 survey completed by students in schools, which showed that $11.5 \%$ of Mãori students had attempted suicide in the past year compared to $5.7 \%$ of NZ European students (Adolescent Health Research Group, 2004) and that 14\% of Pacific students had done so (Adolescent Health Research Group, 2003).

Figures for 2002 show that young Mãori males were almost three times more likely, and young Māori females were twice as likely, to die by suicide than non-Māori young people (Beautrais \& Fergusson, 2006). The rates for Māori males and females between 15 and 24 years were 43.7 and 18.8 respectively per 100,000 population, significantly higher than non-Māori youth suicide rates (18.0 for males and 9.1 for females). Children under the age of 15 rarely commit suicide, but in the 10 -year period from 1989 to 1998, the majority of those New Zealanders who did were Māori (Beautrais, 2001).

Māori adolescents are more likely to have sexual intercourse than non-Māori teens and are less likely to use contraception to protect against sexually transmitted infections (STIs), but are more likely to use contraception to prevent pregnancy (Adolescent Health Research Group, 2001; Clark, Robinson, Crengle, \& Watson, 2006). Birthrates for Māori adolescents are nearly three times higher than those for
European adolescents, and for Pacific adolescents, nearly $21 / 2$ times higher (Jacobsen et al., 2002).

Nearly twice as many Māori youth reported weekly marijuana use as non-Māori and a higher number reported binge drinking (Mãori males 55.02\%, males overall 41.4\%; Māori females 53.74\%, females overall 38.5\%; Adolescent Health Research Group, 2001).

Mental health issues are of concern also, with more Māori being hospitalised and readmitted for mental health issues than Pākehā (Plunkett, 2003).

It is not the purpose of this article to add to the literature regarding the aetiology of these various problems. Cultural alienation and the lack of cultural identity may be factors contributing to poor adjustment in Māori and Pacific youth (Durie, 1994), and a structural approach to depression would argue that the higher rates of depression in Māori are at least somewhat explained by their lower socioeconomic status (Ministry of Health, 2001). This article wishes to acknowledge the risk factors in the lives of Māori and Pacific adolescents outlined above because they highlight the pressing need for attention to be given to the amelioration of existing distress in young people. Further, it is argued here that one part of the solution to high rates of depressive symptoms in Māori and Pacific adolescents might be resilience training through preventative interventions.

School-based resilience programs offer a good catchment strategy in terms of improving accessibility (young people identify lack of access as a barrier to seeking help), and it can compensate for poor help-seeking behaviour in New Zealand adolescents (Adolescent Health Research Group, 2001). Further, the group method as an intervention paradigm has proved to be successful internationally (Trotzer, 2006). Two types of programs, in terms of selected individuals, are typically employed. First, indicated programs are those offered to individuals who have been identified as having some symptoms but who do not meet the full diagnostic criteria for a disorder, and second, universal programs are those offered to a whole cohort regardless of need. Both indicated and universal programs designed to prevent depression have been trialled with some success in Australian and New Zealand schools (Kowalenko et al., 2005; Shochet et al., 2001; Lowry-Webster, Barrett, \& Dadds, 2001; Quayle, Dzuirawiec, Roberts, Kane, \& Ebsworthy, 2001; Merry, McDowell, Wild, Bir, \& Cunliffe, 2004). Evidence supports the use of indicated groups in terms of efficacy and economy (Merry, 2007).

\section{The Current Study}

High rates of depressive symptoms are early indicators of potential full-blown depressive disorder (Harrington, Whittaker, \& Shoebridge, 1998). The present study used the Children's Depression Inventory (CDI) as a screening tool in order to identify students at risk of depression and offered selected students the opportunity 
to participate in the school-based Kiwi ACE program (Woods, 2008). The aim of the intervention was to achieve decreased depressive symptomatology (i.e., lower scores on the CDI) in participants through the use of cognitive-behavioural and psychoeducational techniques. Cognitive-behavioural therapy has been widely evaluated as a successful tool in the treatment of depression (Gillham, Reivich, Jaycox, \& Seligman, 1995, Jaycox, Reivich, Gillham, \& Seligman, 1994). While the program was offered to students of all ethnicities, this article reports on findings from the Māori and Pacific students only.

The Adolescents Coping with Emotions (ACE) program was developed in Australia by a consortium of university and mental health professionals in the late 1990s. During the past ten years over 300 school counsellors have been trained to offer the program in Australia and it has been used in schools in Canada and Denmark for the past three years. The trial by Kowalenko et al. (2005) demonstrated effectiveness in girls. It was first trialled in New Zealand in 2001by the author and then in 2005 in a modified form. Both New Zealand trials demonstrated effectiveness across gender and ethnicity.

\section{Guidelines for Research With Maori}

The Ministry of Māori Development, Te Puni Kokiri (1999) and the Health Research Council of New Zealand (2004), have laid down guidelines for research work with Māori. The guidelines stipulate community consultation that is not strictly a consent issue but rather is an ethical matter in that researchers must ensure that their actions are appropriately sensitive to cultural and social norms (i.e., tikanga or Māori customs and traditions). Any issues relating to Māori cultural and ethical values must be resolved by consultation with the whanau, hapu or iwi (wider family and tribal affiliations) concerned and the mana whenua (people of the area in which the research is taking place). All research proposals must incorporate, where appropriate, the spirit of the Treaty of Waitangi. The intention is for all parties involved in a research project to respect the principles of partnership and sharing implicit in the treaty.

In keeping with these guidelines, consultation took place with elders from Ngati Toa along with professionals from Pasifika mental health groups. A reference group comprising mental health professionals from local Māori and Pasifika groups was formed to have input into the wording and layout of the facilitators' handbooks and student workbooks and into the implementation of the program. Reference group members all had experience working with youth in the mental health area. Cross-cultural, mixed-gender focus groups of students were also set up to review the student workbooks. Suggestions from the groups consisted mainly of small changes to words and pictures, in the reduction of text and the increased use of
Māori and Pacific Island names and cultural designs. As appropriate, aspects of spiritual, mental and physical wellbeing and acknowledgment of the importance of whanau or family (Durie, 1994) were incorporated into the groups along with discussion of issues such as mana (authority or power), whakama (embarrassment or shame) and Māori ways of expressing feelings. The essential message and sequence of the program remained unchanged.

The program has not previously been trialled specifically with indigenous peoples or other particular minority groups and the hypothesis tested with this study was that the program would demonstrate effectiveness in reducing depressive symptomatology (as measured by the Children's Depression Inventory) in Māori and Pacific youth as it does with a whole population sample.

\section{Method}

Four hundred and nineteen Year 10 students (average age 14 years) identifying as Māori and Pacific in eight secondary schools in the North Island of New Zealand were screened for depressive symptoms with the Children's Depression Inventory (Kovacs, 1992) using a passive consent process. Passive consent meant in this case that parents or caregivers and students were advised about the screening but that no signed consents were necessary from either for the student to take part. The process involved informing the young people of the screening through an assembly and form room talks, and the parents through newsletter articles and letters given to students to take home. Parents or caregivers were given the opportunity to contact the school, the researcher or the supervising university with any questions or concerns, and both caregivers/parents and students were informed of the students' right to not participate at any point in the study. This method of consent was chosen because there were seen to be logistical problems with administering the questionnaires in schools where some parents had given consent and others had not, and screening of a whole cohort meant that young people who might otherwise be missed and who might be at risk of depression were identified. New Zealand's high rate of adolescent depression with its associated risks, the low rates of adolescent help-seeking behaviour (Adolescent Health Research Group, 2001), the difficulties in identifying depression in adolescents and the knowledge to be gained about the prevalence of adolescent depressive symptoms was balanced against the knowledge that use of a passive consent process meant that some students would be taking part in the screening without the knowledge of their caregivers. New Zealand schools often use passive consent methods (or no consent) for schoolwide screening of both academic and psychological problems, and schools involved in this case have used this method before for similar purposes. 
Table 1

Ethnicity of Screened, High-Scoring and Selected Students

\begin{tabular}{lccc}
\hline Ethnicity & $\begin{array}{c}\text { \% Students screened } \\
(\mathrm{N}=419)\end{array}$ & $\begin{array}{c}\text { Students }>63 \\
\% \text { on CDI }(\mathrm{n}=83)\end{array}$ & $\begin{array}{c}\text { \% Students randomly } \\
\text { selected for program ( } \mathrm{n}=56)\end{array}$ \\
\hline Maori & $16.5(\mathrm{n}=222)$ & $19(\mathrm{n}=38)$ & $19.2(\mathrm{n}=25)$ \\
Pacific & $14.6(\mathrm{n}=197)$ & $22.5(\mathrm{n}=45)$ & $23.8(\mathrm{n}=31)$ \\
\hline
\end{tabular}

Students ( $n=83$ ) scoring over the 'above average' cutoff point of 63 (Kovacs, 1992) in the screening formed a pool for computer-generated random assignment to intervention and control groups. All students scoring over the cut-off point were followed up by school counsellors, and selected students $(n=56)$ and their caregivers were required to give informed, signed consents prior to participation. Twenty-three students took part in the intervention. Unselected $(n=27)$ and control students ( $n$ $=33$ ) were offered 'usual care', which consisted of the opportunity to have ongoing counselling with the school counsellors or referral to mental health services where student safety was of concern. As stated earlier, these participants formed part of a larger study across all ethnicities and consequently the randomisation process meant that Māori and Pacific students were unevenly distributed into intervention and control groups and those offered usual care.

Students were tested at five points: screening, pretest, posttest, follow-up at 8-weeks' postintervention and 1year post-intervention. A flow chart using the CONSORT guidelines showing numbers of participants at each test point appears in Figure 1. In order to test for the possible effect of a pretest, a four-group design was used

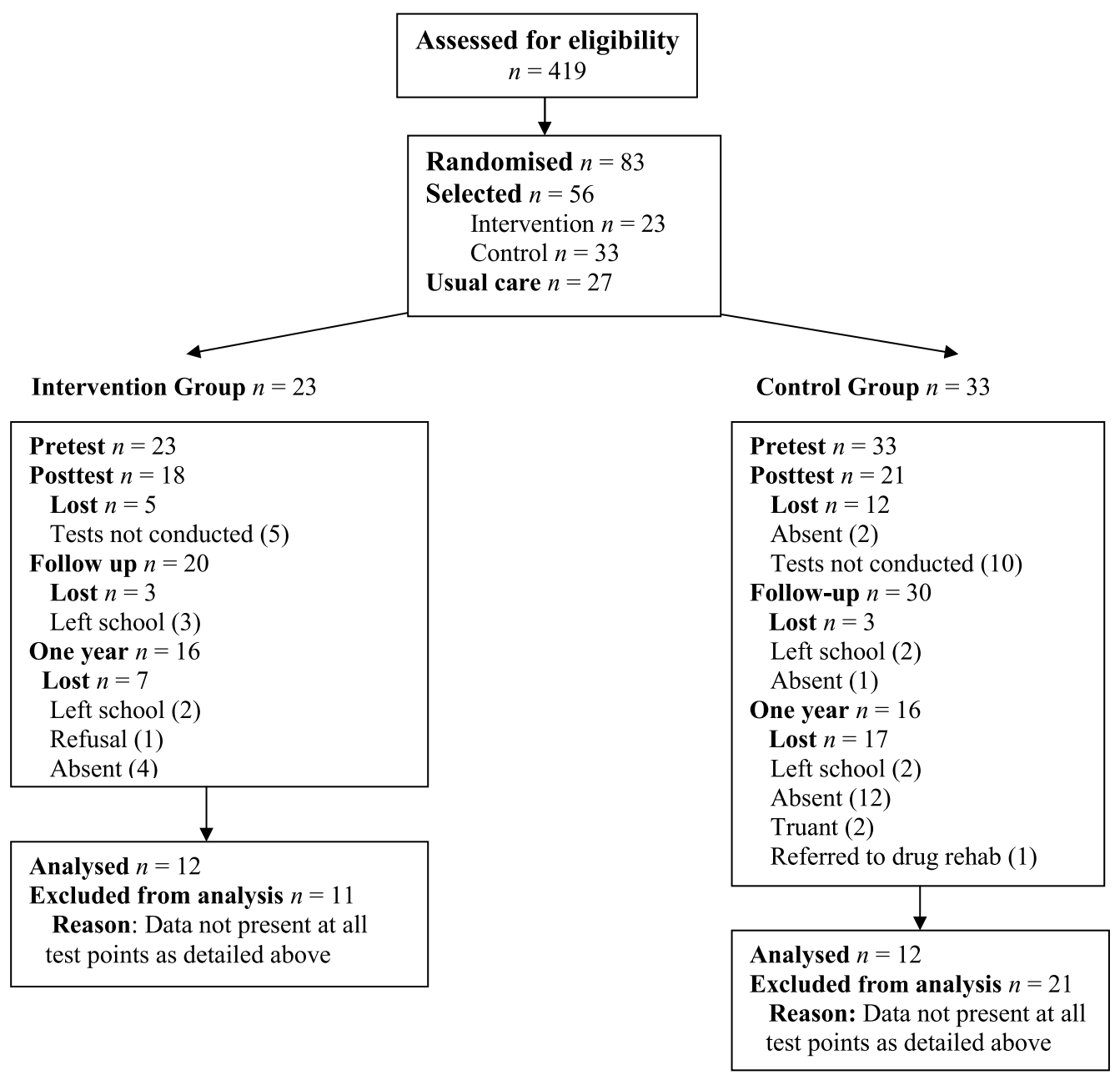

Figure 1

Flow diagram showing the movement of participants through each stage of the Kiwi ACE randomised trial. 
(Solomon, 1948), with two groups in each of the intervention and the control groups. Half of the individuals in the intervention and control groups completed the CDI at pretest, and half did not. In eight schools, groups were cross-cultural and in one school the intervention group consisted entirely of Māori and Pacific students.

\section{Participants}

Schools were selected from across the socioeconomic range using Ministry of Education decile rankings (Ministry of Education, 1997). Two of the schools were drawn from the Wellington metropolitan area, which statistically is a better-educated and higher-income area than the average sector of New Zealand (Statistics New Zealand, 2003). Five schools were located in the greater metropolitan area, which is diverse in terms of income and ethnicity and one school was from a provincial city, replacing a metropolitan school that had to withdraw immediately prior to the screening process because of ill health of the school counsellor. About $45 \%$ of the students in the present study identified as Māori and 55\% as Pacific (see Table 1).

\section{Allocation to Intervention or Control Group}

Students were randomly allocated to intervention and control groups $(n=56)$, but a complete dataset (comprising data at all test points) is available for only 24 students (see Figure 1). Reasons for not completing measures at various test points include students moving between schools, absence, truancy, referral to an outside agency and one facilitator failed to obtain posttest results from one group. There was no significant difference $(p>.05)$ at screening in scores between those who completed data at all test points and those who did not.

\section{Measures}

The CDI is a very widely used questionnaire that is suitable for screening as it has predictive value for the identification of risk of depression in adolescents (Sitarenios \& Kovacs, 1999; Timbremont, Braet, \& Dreessen, 2004), and it has demonstrated content validity in the New Zealand context with Maori and Pacific adolescents (e.g., Jose \& Schurer, 2010). It contains 27 items measuring depressive symptomatology including disturbed mood, hedonic capacity, vegetative functions, self-evaluation, hopelessness and interpersonal behaviours. Each item lists three possible responses, and the respondent is asked to choose the one response in each triad that describes how they have felt recently. For example, one item concerning sadness is composed of these three options: 'I am sad once in a while' (1); 'I am sad many times' (2); and 'I am sad all the time' (3).The items are quantified on a scale of $1-3$, and approximately half of the items are reverse ordered. The possible raw score range is $27-81$, and a score of between $45-55$ is considered average, with $56-60$ being slightly above average, 61-65 above average, 66-70 much above average, and over 70 very much above average (Kovacs, 1992). A $T$ score of 63 (the middle of the 'very much above average' range) or over was selected as the cut-off for this study (Kovacs, 1992) in order to form a pool for the selection of the intervention and control groups. A score in this range allows for the selection ratio of true positives and false positives from a normative population to be maintained and at the same time to minimise the number of false positives (Kovacs, 1992). The CDI is reported by Kovacs (1992) as yielding high test-retest reliability and possessing high internal consistency (a Cronbach's alpha of .86). Kovacs (1992) reported good short-term stability and test-retest reliability with scores ranging from .38 to .83 in nonpsychiatric populations, but other reviewers have found that the test-retest reliability was highly variable (Myers \& Winters, 2002). Despite the variation in findings regarding the reliability of the $\mathrm{CDI}$, it has a wide normative base and strong psychometric properties and is the most widely used and studied scale for adolescent depression (Myers \& Winter, 2002).

\section{Procedure}

Over the eight weeks of the program, students were taught to appreciate the relationships between thinking, feeling and behaviour, and to challenge thoughts and beliefs. Problem-solving and personal and social skills and strategies were developed using exercises, role-plays, rehearsals and structured personal discussions. Sessions were included that focused on the use of pleasurable activities that increase positive feeling and the changing of unproductive habits. To increase the use of pleasurable activities, a 'Fun form' was introduced and students used a ranking scale to measure feelings before and after pleasurable activities. They were encouraged to compete in generating five ways in which they could have more pleasurable experiences in each day. The idea was promoted that 'moments' of pleasure are worthwhile and that moments of pleasure need not incur a high cost financially. To increase motivation to change unproductive habits, students were asked to choose something they would like to change, such as swearing, cigarette or marijuana smoking or alcohol use, and to complete a 'balance sheet' about the habit, of 'good things about it' and 'not so good things about it'. This activity in itself is often productive in terms of beginning to change motivations. Students then completed the sentence: 'I want to change because ...' and set a small, achievable goal for themselves for the coming week. They used scaling to explore how important the goal was to them, and how confident they were of achieving that goal; and supports for changing behaviours were identified, along with 'triggers' for the undesired behaviours. Students were encouraged to recall the last time they engaged in the undesired behaviours, the triggers in that particular situation and the immediate and delayed consequences that 
followed the behaviour. An Action Plan was drawn up with optional behaviours and their consequences, the behaviour triggers and the management strategies for those. A Back-up Plan was called for and the idea of relapse was introduced with the words 'If you mess up - you can learn from it - tomorrow is another day!' (Woods, 2008).

The section on changing unproductive habits was based on Sobell's guided self-change (Sobell \& Sobell, 1993) and motivational interviewing (Miller \& Rollnick, 2002) and was included in response to anecdotal feedback from facilitators in the author's earlier trial to assist students who were experiencing challenges with substance use. Students had the opportunity within the safety of the group to learn from, and to support, each other. This learning is an important protective mechanism that fosters resilience, connectedness and a sense of efficacy and wellbeing in the students (Durlak \& Wells, 1998).

The intervention ran over 8 weeks in school time with one 90-minute session weekly. Groups comprising between eight and ten students were facilitated by school counsellors working with a second school-based professional. The cofacilitators comprised variously resource teachers of learning and behaviour (RTLBs), social workers and youth workers.

To ensure fidelity to the program, facilitators attended $1 \frac{1}{2}$ days of training run by the author and were issued a facilitator handbook and a student workbook. Two further meetings and telephone contact were provided during the course of the program for feedback and support.

All eight schools approached agreed to take part in the study. The schools consisted of five state coeducational schools, one state single-sex girls' school, one integrated single-sex girls' school and one integrated single-sex boys' school. All Year 10 (average age 14 years) Maori and Pacific students were screened, with all stakeholders being made aware of the aims and time frames of all aspects of the program and its implementation.

\section{Data Analysis}

A two-way ANOVA with repeated measures, with the between-subjects variable being the intervention and the within-subjects variable being time, was conducted to determine whether the intervention affected CDI scores after the experimental phase. The use of the four-group design to test for the effect of a pretest meant that data were not available for some students at pretest. Screening scores were carried forward for these students (7 in the intervention group and 15 in the control group), and this procedure assumes no change in scores. The CDI was used for screening as well as posttreatment assessments in order to more accurately track change in depressive symptoms (i.e., use of the same measure put these scores on the same metric).
With a design such as was used here (i.e., sampling individuals from a set of schools) one may obtain nonindependent observations within schools, which would increase the risk of type I error (Kenny, 2011). In order to determine whether significant pooling of variance occurred within school (level 2), a multi-level analysis with Raudenbush, Bryk, and Congdon's (2004) Hierarchical Linear Modelling ${ }^{\mathrm{TM}}$ software (Version 6.06) was performed on CDI scores at screening, pretest, immediate posttest, and one-year follow-up. The variance component for schools was nonsignificant in all cases, $\chi^{2}(8)=3.53$ to 13.24 , all $p s>.10$; ICCs $=.13$ to .01 . Thus, we proceeded under the assumption that CDI scores of individuals were not constrained by school membership and therefore we did not have a nested dataset.

\section{Ethics and Safety}

The study was approved by the Deakin University Higher Research Ethics Committee. The committee was familiar with research issues concerning Indigenous youth (in their particular case, Aboriginal peoples), although it was unclear and probably unlikely that they had a Pacific Islander or Maori representative on their committee. In any case, they raised appropriate cautions concerning research with such a population and we endeavoured to be sensitive and respective to these concerns during the course of the research. The reference group also ensured that we conducted the research in a culturally appropriate fashion.

Students deemed to be at risk of harm were managed with the usual school procedures. Facilitators monitored identified students in addition to administering questionnaires to participants at the various test points. No student appeared to be adversely affected by participation in the study and no students withdrew because of worsened mood.

\section{Results}

\section{Changes in Depressive Symptomatology}

A repeated measures analysis of variance compared the intervention group against the control group across the four times of measurement. A significant treatment by time interaction was predicted, namely that the two groups were expected to diverge after the experience of the intervention for the experimental group, and this interaction was found in the present data, $F(3,66)=$ $4.30, p<.01$, partial $\eta^{2}=.16$, yielding a large effect size (Cohen, 1988). The group means by time are reported in Table 2 and displayed in Figure 2. Follow-up posthoc $t$ tests were computed at each of the four time points separately. As expected, no difference was obtained at the pretest, $t(54)=-.26, p=.80$, however, a significant difference was obtained both at immediate posttest, $t(37)=$ $-2.08, p=.045$, and at one-year follow-up, $t(30)=-5.64$, $p=.001$. The difference at follow-up was in the expected direction, but was not statistically significant, $p=.22$. 
Table 2

CDI Scores: Intervention and Control Groups' Means and Standard Deviations at all Test Points

\begin{tabular}{lccc}
\hline Group & Mean & Standard Deviation & $\mathrm{n}$ \\
\hline $\begin{array}{l}\text { Screening } \\
\quad \text { Intervention }\end{array}$ & 26.75 & 6.22 & 12 \\
$\quad$ Control & 26.33 & 3.96 & 12 \\
$\begin{array}{l}\text { Pretest } \\
\quad \text { Intervention }\end{array}$ & & & \\
$\quad$ Control & 22.92 & 6.63 & 12 \\
Posttest & 26.17 & 4.32 & 12 \\
$\quad$ Intervention & & & \\
$\quad$ Control & 13.33 & 7.22 & 12 \\
Follow-up & 22.33 & 7.78 & 12 \\
$\quad$ Intervention & & & \\
$\quad$ Control & 10.67 & 6.12 & 12 \\
1 year & 15.67 & 7.02 & 12 \\
$\quad$ Intervention & & & \\
$\quad$ Control & 11.92 & 7.04 & 12 \\
\hline
\end{tabular}

The size of the difference between the two groups that was attributable to participation in the intervention was 13.42 points on the CDI at the last time point. Means and standard deviations are presented in Table 2 and in Figure 2. It can be seen that while the control group means regressed to preintervention levels at one year, the means of the intervention group did not.

\section{Focus Groups}

The focus groups were semistructured and facilitated by the first author. The main aim was to gather personal descriptions from the students about the coping skills they had used to deal with problems over the time of the study and the reasons for any changes that might have occurred in their use of these skills. The students were asked questions about pressures and problems they believed were faced by young people and about the general coping styles that are used by their peers. Further, they were asked what had been helpful and not helpful about the Kiwi ACE program. The students were then asked to write anonymously about some of their own personal problems and coping styles and to identify changes and reasons for these changes that might have occurred in these domains over time.

Pressure to use drugs, to be thin, and to have sex were identified by girls as being the biggest problems they faced, and for boys it was the pressure to use drugs. In addition, the topic of ethnic discrimination was mentioned by two groups. Girls in one group spoke of people looking 'down on you ... your colour. You know, Miss, us brownies', and a boy in another school reported that 'Asians get a lot of rap as well.'

Coping styles identified by the participants were mainly maladaptive, with the use of drugs being named most frequently, and aggressive behaviours that included swearing and fighting being named by both boys and girls. Girls also identified smoking, crying, running away, self-inflicted injury and depression as methods of coping. Both boys and girls named 'ignoring' a problem as a strategy and several girls mentioned using helpseeking behaviours. One girl was helped by her faith and one boy identified having 'a laugh' as useful in coping.

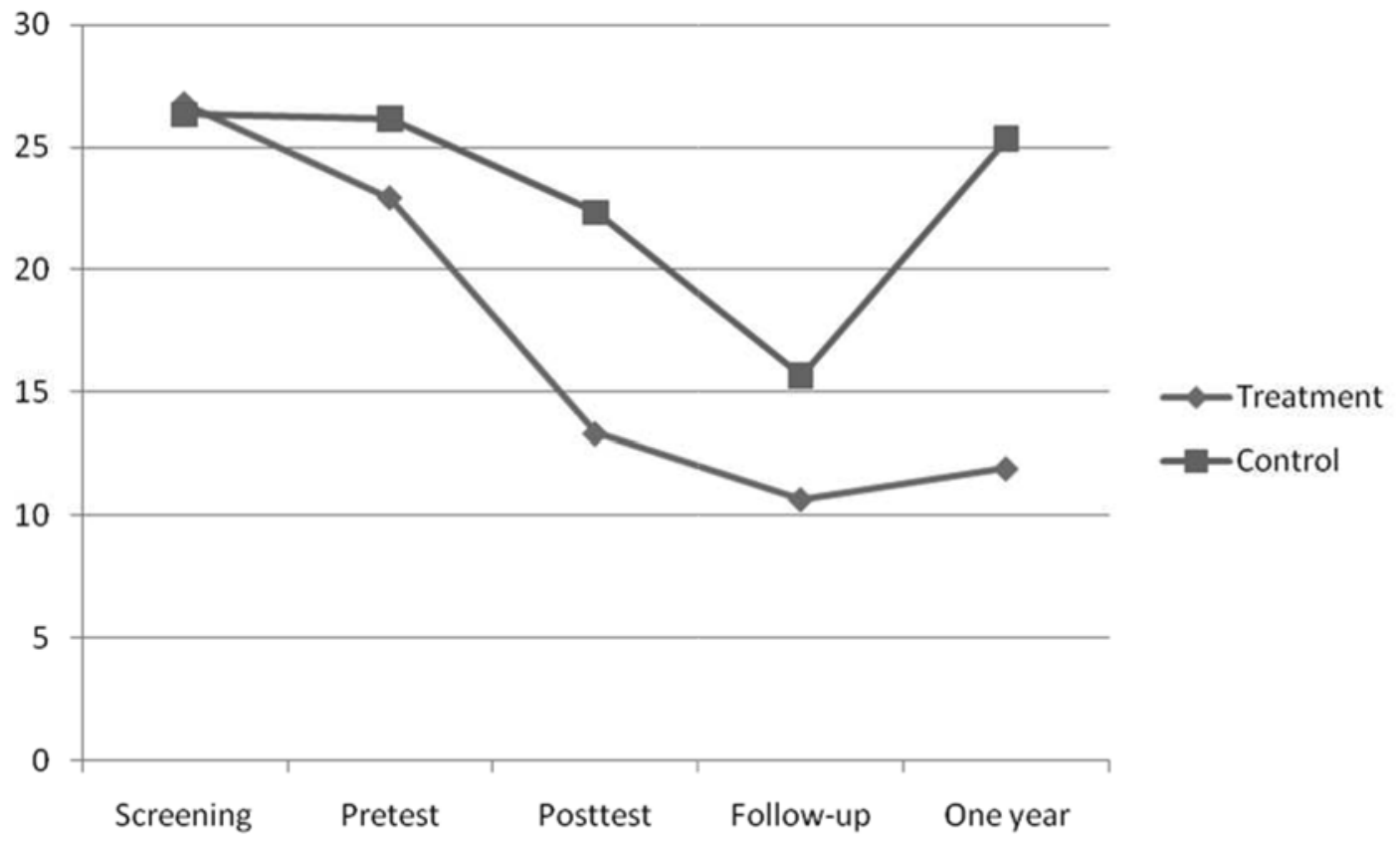

Figure 2

Depressive symptom (CDI) scores for the treatment and control groups over time. 
Feedback about the program identified trust in the group as an important benefit (from several girls and one boy) and insight gained about thinking processes was considered useful by six girls and two boys. Confectionery supplied as rewards was mentioned as important to both boys and girls, and several identified the games played and missing class as good aspects of the program. Individual students found the sections on goal-setting, changing bad habits, the thinking scenarios and anger management sections of benefit.

The biggest objection students had to the program concerned the amount of reading and writing involved and what they perceived as 'out-of-date' scenarios. The girls who identified the scenarios as out-of-date believed that the scenarios featuring the use of negotiation and conflict resolution should focus on physical fighting as this was an issue for many of them. They described 'gang warfare', 'getting the bash' and 'walking the gauntlet'. 'Walking the gauntlet' occurs when one person, 'A', has to run between two lines of 'enemies' who throw as many hits and punches as they can while ' $\mathrm{A}$ ' is running as fast as possible through the gap between the lines of enemies. Completing the run and not showing fear means that 'A' is 'staunch' and can 'take it'.

\section{Identified 'Problems' and Coping Skills After the Intervention}

Eight of the respondents described 'fighting' or 'arguing' as a problem and reported coping by going for walks, reading books, listening to loud music, staying realistic, 'just taking the blame', not having a 'tempy', blocking it out - but that did not work so they approached the person 'in a different way', and talking about it.

Two students identified 'study' as a problem. One created a 'Study program \& I'm going to start studyn 2nite' and another did 'What parents say'. One student was asked to smoke 'With cool people ... and decided not to'. Another had a friend who 'Attempted suicide' and they 'talked to them and got help'. Another student wanted to 'Kill self', talked to the school counsellor and 'now it's all gud'. Two students identified bullying as a problem, with one student telling the bullier to 'Shut the - up' and the other just taking 'The blame for things I didn't do'.

The methods of new coping described appeared in almost all cases to be constructive, with students taking positive and pro-active steps to avoid or deal with problems.

\section{Past Coping Skills}

When asked to think 'back to a term ago, of a similar pressure or problem', and how they had dealt with them then, students identified many more methods of coping used at that time that were likely to lead to further problems (i.e., be maladaptive).

Three students had attempted suicide; two cut themselves; six students 'Threw things' or 'Smashed' or 'Trashed' the house; four 'Ran away'; four 'Walked out', (one in a 'tempy'); six 'Fought', one 'Beat up [their] brother); five 'Yelled' (one 'Screaming \& throwing a metal [sic] breakdown'); three 'Avoided things'; one 'Didn't talk'; one 'Said no I wouldn't do things \& did them anyway'; four smoked (they did not specify what they were smoking); one 'Partied to get mind off things'; and one 'Beed sad'. Others used methods potentially less damaging: two 'Ignored it', one 'Told my dad', one 'Talked about it', and one 'Went to rowing'.

\section{Differences Between Present and Past Coping Skills}

The majority of students identified positive changes in their coping strategies. However, one wrote about negative coping strategies used, two said there was no change in the ways they were coping and two students gave no response. The following differences were described. Three students said they were 'Not cutting any more' with one reporting 'Actually lik[ing] life'. One student reported 'Not doing a runner', four 'Manage[d] anger a lot better', and four said they 'Don't fight' (not having 'big tempys now'). Three students reported that they were 'Cutting down', four reported 'Thinking more/clearer', five said they talk to people now 'Instead of keeping it inside', and one student identified 'Speaking differently to my mother'. Only two students described negative changes, with both reporting 'Drinking' and one of them describing how she 'Screamed at her mother'.

The reduction in self-harm described, the constructive management of anger and the positive changes in ways of thinking, communicating and seeking support about problems are adaptive changes, as is the reduction in nonproductive ways of coping ('Cutting down') described by three students. Improvements in the ways of coping described by the students far outweigh the negative coping skills described by a few others.

\section{Student Hypotheses About Changes}

Students identified program content specifically in their responses when asked what helped them to make the changes. Five students identified 'Stuff in that book' and three specifically identified 'Realistic thinking' ('They rock' was the feedback from one student). The 'Stuff on Bad Habits' was identified and 'Not letting anger get the better of me' along with 'Not fighting' and 'Talking to counsellor/coach'. Two said 'Dunno' and one said 'Alcohol and smoking. Three students gave no response.

\section{Discussion}

This study sought to determine the effectiveness of an early intervention program targeting young people identified as being at risk of depression. Participants reported significantly lower levels of depressive symptomatology as measured by the CDI immediately after and at one year postintervention. This result supports the main hypothesis that the ACE Kiwi program would be effective in reducing depressive symptoms in Maori and Pacific 
youth over time. The prevention effect seemed to grow over time and this finding echoes those by Kane (2000), Gillham et al. (1995), and Jaycox et al. (1994). It may be that learning is cumulative and self-reinforcing. The small numbers of individuals in the study reduced statistical power and this fact may have prevented finding an effect for the intervention at the follow-up ( 8 weeks).

Students identified positive changes in the ways in which they managed and regulated negative emotions and coped with problems, noting a reduction in high-risk behaviours towards themselves, others and property, and improved ways of thinking and communicating and the defusing of upsetting situations.

The adolescents identified drugs/alcohol and conflict as their main concerns and, while the teaching of skills to manage these issues is taught in classrooms as part of the New Zealand school health curriculum (Ministry of Education, 1997), clearly there are young people who feel ill equipped to deal with these and other problems. It may be that for some of these students these skills are more effectively learned in small group situations rather than as curriculum subjects in a mainstream classroom, and that this needs to occur for targeted groups or individuals. The group method as a paradigm has proved successful internationally (Blakeley, 2005) and appears to be useful in particular for Maori and Pacific young people. Skilled facilitation is of prime importance, and the group must have a focus on relationship building (Shechtman, 2007) or, as it is termed within the Maori context, whanaungatanga.

Recruitment of students was performed very well and the program was well-received by the facilitators of the program. Facilitators reported increases in help-seeking behaviour, positive social interactions, personal confidence and interpersonal trust in participating students. These positive changes were supported by anecdotal evidence from local mental health professionals that young people referred to their service who had been through the earlier trial of the program (Woods, 2001) were more resilient than young people who had not received the program.

A concern of the facilitators was that these individuals might struggle with a program that is enacted with a fair amount of reading and writing, since many of the young people struggle with literacy, but this was seemingly not the case. The participants seemed to be able to read the materials to an adequate level and write when appropriate. Feedback from students emphasised the importance of future group facilitators using student-generated scenarios for the practice of skills in the program.

\section{Limitations}

The use of a sample drawn exclusively from a metropolitan area means that the results may not generalise well to rural youth. The sample's small size reduces our confidence that this result would be generally obtained for Maori and Pacific youth in New Zealand. Facilitators came with varied skill levels in cognitive-behavioural techniques and the differences in program delivery and facilitation skills meant that the quality of the delivery of the program varied across the schools.

While there is often a concern about the issue of stigmatisation with indicated programs, Rapee et al. (2006) have found the effect size to be small and limited to males. Feedback given by students in the current study was that stigmatisation 'wasn't an issue'. Referral to a community mental health clinic is likely to carry greater stigmatisation than that experienced through referral to a school-based group (Marcotte et al., 2002).

\section{Clinical Implications}

Given the high rate of Maori and Pacific adolescent depressive symptomatology in New Zealand, there is an urgent need for further testing of preventive interventions for these youth. School-based programs based on cognitive restructuring and improving coping skills that target young people at risk of depression (Harrington \& Dubicka, 2002) could overcome some of the barriers to obtaining needed health support identified by adolescents and form part of an overall strategy to improve the health and integration of adolescents into society. Further longitudinal studies are needed to replicate the study and to establish the durability of the effects of participation in the program.

\section{Author Notes}

Appreciation is expressed to the staff and students of the schools, facilitators, and cross-cultural advisers who assisted with the study and to Drs Lyn Harrison, Peter Smith, Ann Wignall and Nick Kowalenko for their support and advice.

\section{References}

Adolescent Health Research Group. (2001). New Zealand youth: A profile of their health and wellbeing. Auckland, New Zealand: University of Auckland.

Adolescent Health Research Group. (2003). New Zealand Youth: A profile of their health and wellbeing. Auckland, New Zealand: University of Auckland.

Adolescent Health Research Group. (2004). Te Ara Whakapiki Taitamariki: Maori-specific findings of Youth2000. Auckland, New Zealand: University of Auckland.

Adolescent Health Research Group. (2008). Youth'07: The health and wellbeing of secondary school students in New Zealand. Initial findings. Auckland, New Zealand: The University of Auckland. Retrieved March 27, 2009 from http://www. youth2000.ac.nz/publications/reports-1142.htm

Beautrais, A.L., \& Fergusson, D.M. (2006). Indigenous suicide in New Zealand. Archives of Suicide Research, 10, 159-168.

Beautrais, A.L. (2001). Suicide \& suicidal behaviour amongst Maori youth. Canterbury Suicide Project. Retrieved October 4, 2009 from http://www.chmeds.ac.nz/research/ suicide/pdfs/maori\%20and\%20pacific\%20youth.pdf

Berndt, E.R., Koran, L.M., Finkelstein, S.N., Gelenberg, A.J., Kornstein, S.G., Miller, I.M., ... Keller, M.B. (2000). Lost 
human capital from early-onset chronic depression. American Journal of Psychiatry, 15, 940-947.

Blakely, C. (2005). Review of group treatment of adolescents in context. Studies in Social Work, 75(2), 121-125.

Clark, T., Robinson, E., Crengle, S., \& Watson, P. (2006). Contraceptive use by Maori youth in New Zealand: Associated risk and protective factors. Journal of the New Zealand Medical Association, 119(1228), U1816.

Cohen, J. (1988). Statistical power analysis for the behavioral sciences (2nd ed.). Hillsdale, NJ: Lawrence Erlbaum.

Costello, E.J., Pine, D.S., Jammen, C., March, J.S., Plotsky, P.M., \& Weissman, M.M., et al. (2002). Development and natural history of mood disorders. Biological Psychiatry, 52(6), 529-542.

DiClemente, R.J. (2001). Distress increases risk of pregnancy in adolescents. Retrieved November 19, 2001 from http://psychiatry.medscape.com/reuters/prof/2001/11/11.20011109cl in015.html

Durie, M. (1994). Whaiora: Maori health and development. London: Oxford University Press.

Durlak, J.A., \& Wells, A.M. (1998). Evaluation of indicated preventive intervention (secondary prevention) mental health programs for children and adolescents. American Journal of Community Psychology, 26(5), 775-802.

Fergusson, D.M., Boden, J.M., \& Horwood, L.J. (2007). Recurrence of major depression in adolescence and early adulthood, and later mental health, educational and economic outcomes. British Journal of Psychiatry, 191, 335-342.

Fergusson, D.M., \& Horwood, L.J. (2001). The Christchurch Health \& Development Study: Review of findings on child and adolescent mental health. Australian and New Zealand Journal of Psychiatry, 35, 287-296.

Gillham, J.E., Reivich, K.J., Jaycox, L.H., \& Seligman, M.E.P. (1995). Prevention of depressive symptoms in schoolchildren: Two year follow-up. Psychological Science, 6, 343-351.

Harrington, R. (2001). Depression, suicide and deliberate selfharm in adolescence. British Medical Bulletin, 57, 47-60.

Harrington, R., \& Dubicka, D. (2002). Adolescent depression: An evidence-based approach to intervention. Current Opinions in Psychiatry, 15, 369-375.

Harrington, R., Whittaker, J., \& Shoebridge, P. (1998). Psychological treatment of depression in children and adolescents. British Journal of Psychiatry, 173, 291-298.

Hauenstein, E.J. (2003). Depression in adolescence. Journal of Obstetric and Gynecological Neonatal Nursing 32, 239-248.

Health Research Council of New Zealand. (2004). Ng Pou Rangahau Hauora Kia Whakapiki Ake Te Hauora M ori 2004-2008. The Health Research Strategy to Improve $M$ ori Health and Well-being 2004-2008. Retrieved November 6, 2010 from http://www.hrc.govt.nz/assets/pdfs /publications/Strategic\%20Plan\%202004-2008.pdf

Horomia, P. (2007). Maori student achievement improving. Retrieved October 5, 2009 from http://www.beehive. govt.nz/release/maori+student+ achievement+improving

Jacobsen, V., Mays, N., Crawford, R., Annesley, B., Christoffel, P., Johnston, G., \& Durbin, S. (2002). Investing in wellbring: An analytical framework (New Zealand Treasury Working Paper 02/23). Retrieved October 5, 2009 from http://www.treasury.govt.nz/publications/researchpolicy/wp/2002/02-23/twp02-23.pdf

Jaycox, L.H., Reivich, K.J., Gillham, J., \& Seligman, M.E.P. (1994). Prevention of depressive symptoms in schoolchildren. Behaviour Research \& Therapy, 32, 801-816.

Jose, P.E., \& Schurer, K. (2010). Cultural differences in coping among New Zealand adolescents. Journal of Cross-Cultural Psychology, 41(1), 3-18.

Joyce, P.R., Oakley-Browne, M.A., Wells, J.E., Bushnell, J.A., \& Hornblow, A.R. (1990). Birth cohort trends in major depression: Increasing rates and earlier onset in New Zealand. Journal of Affective Disorders, 18(2), 83-89.

Kane, T.A. (2000). The treatment of depression in adolescents: Four case reports. Unpublished doctoral dissertation, Deakin University, Australia.

Kenny, D.A. (2010). Home page. University of Connecticut, Storrs, CT. Retrieved March 19, 2011, from http://davidakenny.net/kenny.htm

Kovacs, M. (1992). Children's Depression Inventory. Toronto, Canada: Multi-Health Systems, Inc.

Kowalenko, N., Rapee, R.M., Simmons, J. Wignall, A., Hoge, R., Whitefield, K., ... Baillie, A.J. (2005). Short-term effectiveness of a school-based early intervention program for adolescent depression. Clinical Child Psychology \& Psychiatry, 10(4), 493-507.

Lawson-Te Aho, K. (1998b). A review of evidence: A Background Document To Support Kia Piki te Ora o te Taitamariki: Strengthening youth wellbeing: New Zealand youth suicide prevention strategy. Wellington, New Zealand: Ministry of Maori Development.

Lowry-Webster, H.M., Barrett, P.M., \& Dadds, M.R. (2001). A universal prevention trial of anxiety and depressive symptomatology in childhood: Preliminary data from an Australian study. Behavior Change, 18(1), 36-50.

Marcotte, D., Fortin, L., Potvin, P., \& Papillon, M. (2002). Gender differences in depressive symptoms during adolescence: Role of gender-typed characteristics, self-esteem, body image, stressful life events, and pubertal status. Journal of Emotional \& Behavioral Disorders, 10(1), 2929-2942.

Merry, S.N. (2007). Prevention and early intervention for depression in young people: Practical possibility? Current Opinions in Psychiatry, 20(4), 325-329.

Merry, S., McDowell, H., Wild, C.J., Bir, J., \& Cunliffe, R. (2004). A randomized placebo controlled trial of a schoolbased depression prevention program. Journal of American Academy of Child \& Adolescent Psychiatry, 43, 538-547.

Miller, W.R., \& Rollnick, S. (2002). Motivational interviewing: Preparing people for change. New York: The Guilford Press.

Ministry of Education. (1997). Ministry of Education socio-economic indicators for schools. Wellington, New Zealand: Ministry of Education Data Management and Analysis Section.

Ministry of Education. (1997). Health and physical education in the New Zealand curriculum. Wellington, New Zealand: Learning Media.

Ministry of Health. (2001). Monitoring ethnic inequalities in health (Public Health Intelligence Occasional Bulletin No. 
4). Retrieved March 7, 2007, from http://www.moh.govt. nz/moh.nsf/0/a4bceba4fe65795bcc256a7700839825/\$FILE/ ATTDJSLT/MonitoringEthnicInequalities.pdf

Ministry of Health. (2006). Suicide facts: Provisional 2003. AllAges Statistics (Public Health Monitoring Report No. 1). Wellington, New Zealand: Ministry of Health. Retrieved February 21, 2007, from http://www.moh.govt.nz/suicideprevention

Ministry of Maori Development. (1999). Evaluation for Maori: Guidelines for Government Agencies. Wellington, New Zealand: Ministry of Maori Development.

Myers, K., \& Winters, N.C. (2002). Ten-year review of rating scales. II: scales for internalizing disorders. Journal of the American Academy of Child \& Adolescent Psychiatry, 41(6), 634-59.

National Institute of Mental Health. (2000). Depression in children and adolescents. Retrieved November 11, 2001 from http://www.nimh.nih.gov/publicat/depchildresfact.cfm

Parker, G., \& Roy, K. (2001). Adolescent depression: A review. Australian and New Zealand Journal of Psychiatry, 35, 572-580.

Plunkett, F. (2003). Epidemiology: Maori Mental Health. Retrieved October 5, 2009 from http://www. teiho.org/ Epidemiology/DisparitiesInMaoriMentalHealth.aspx

Quayle, D., Dzuirawiec, S., Roberts, C., Kane, R., \& Ebsworthy, G. (2001). The effect of an optimism and lifeskills program on depressive symptoms in preadolescence. Behavior Change, 18(4), 194-203.

Rao U. (2001). Sleep patterns predict depression in adolescents. Retrieved October 10, 2001, from www.medscape.com /reuters/prof/2001/10/10.30/20011029clin007.html

Raudenbush, S.W., Bryk, A.S., \& Congdon, R. (2004). HLM 6 for Windows [Computer software]. Lincolnwood, IL: Scientific Software International, Inc.

Rapee, R.M., Wignall, A., Sheffield, J., Kowalenko, N., Davis, A., McLoone, J., \& Spence, S.H. (2006). Adolescents' reactions to universal and indicated prevention programs for depression: Perceived stigma and consumer satisfaction. Prevention Science, 7(2), 167-177.
Shechtman, Z. (2007). How does group process research inform leaders of counseling and psychotherapy groups? Group Dynamics: Theory, Research, and Practice. Special Issue: Groups in educational settings, 11(4), 293-304.

Shochet, I.M., Dadds, M.R., Holland, D., Whitefield, K., Harnett, P.H., \& Osgarby, S.M. (2001). The efficacy of a universal school-based program to prevent adolescent depression. Journal of Clinical Child Psychology, 30, 303-315.

Sitarenios, G., \& Kovacs, M. (1999). Use of the Children's Depression Inventory. In M.E. Maruish (Ed.), The use of psychological testing for treatment planning and outcomes assessment (2nd ed., pp. 267-298). Mahwah, NJ: Lawrence Erlbaum \& Associates.

Sobell, M.B., \& Sobell, L.C. (1993). Problem drinkers: Guided self-change treatment. New York: The Guilford Press.

Solomon, R.L. (1948). An extension of control group design. Psychological Bulletin, 46, 137-150.

Statistics New Zealand. (2003). Ethnic groups, 2002. Retrieved August 7, 2006 from http://www.stats.govt.nz/NR/rdonlyres/988C1E07-45FD-4A14-8164-393B5CFDF513/0/Eth nicGroups01.pdf

Timbremont, B., Braet, C., \& Dreessen, L. (2004). Assessing depression in youth: Relation between the Children's Depression Inventory and a structured interview. Journal of Clinical Child and Adolescent Psychology, 33(1), 149-157.

Trotzer, J.P. (2006). The counselor and the group: Integrating theory, training, and practice (4th ed.). New York, NY: Routledge/Taylor \& Francis.

Woods, B.R. (2001). Kiwi ACE: An indicated preventive depression programme in schools (Report to Ministry of Education, New Zealand). Wellington, New Zealand: Ministry of Education.

Woods, B.R. (2008). Kiwi ACE: A school-based preventive depression programme. Unpublished doctoral dissertation. Deakin University, Australia.

World Health Organization. (2005). Mental health. Retrieved 30 September, 2005 from http://www.who.int/ mental_ health/management/ depression/definition/en/ 